\title{
HEALTH CARE AND SUBJECTIVE WELL-BEING IN NATIONS
}

\author{
Bruce Kirkcaldy, Adrian Furnham and Ruut Veenhoven
}

\author{
Published in: Antoniou, A.S.G. \& Cooper C. L . (eds) Research Companion to Organi- \\ zational Health Psychology, Edward Elgar Publishers, 2005, Cheltenham UK). \\ ISBN 184376 6248, pp: 393-412
}

\section{The issue}

With the ever-increasing costs incurred by medical health care in the majority of the industrialized nations of the world, attempts have been made to identify and rectify the deficiencies in the health industry and improve quality management assessment. A central question for politicians and researchers is, to what extent does a country's health care system influence the subjective well-being in its citizens?

The World Health Report 2000 has been published in an attempt to evaluate diverse health services across the world with a view to comparing performance, and enabling policy makers to appreciate better the complexity of health care. Consequently, in 'unprecedented degree it takes account of the role of people as providers and consumers of health services, as financial contributors to health systems, as workers within them, and as citizens engaged in their responsible management, or stewardship' (WHO, 2001).

It has been reported that only four of the 191 member nations of the World Health Organisation spend in excess of 10 per cent of the GDP on health services. These are the USA, Germany, Lebanon and Switzerland. The World Health Report suggests that the expenditure is not reflected in superior quality health service, with nations such as the USA being placed $37 \mathrm{th}$, Germany 25th and Switzerland 20th. The nations ranked amongst the top ten in terms of overall health performance are France (1), Italy (2), San Marino (3), Andorra (4), Malta (5), Singapore (6), Spain (7), Oman (8), Austria (9) and Japan (10).

Several reasons account for the enormous health care expenditures in many of the Western industrialized nations. One factor is related to size and structure of the population (demographic data such as size, age and gender), with, for example, increasingly large numbers of older citizens, and rising public expectations concerning quality of medical health care. Another important source of escalating costs is the increasing innovations in health care technology. They enhance prevention and treatment of ailments and consequently increase the duration and quality of life:

Technology innovation for health care promotes the industrial sector and has tremendous potential to reduce costs. However, health care technology resources are not always deployed in an optimal fashion: wasteful provision and utilisation by those who provide and utilise health care technology is often attributed to a lack of cost-consciousness. New health care technology is frequently acquired and utilised without clear evidence that it provides a better and cheaper or more cost effective alternative to existing technologies. (Jakubowski and Busse, 1998)

In commenting about what constitutes an effective health system, the World Health Report notes:

it is not always satisfactory to protect or improve the average health of the population, if at the same time inequality worsens or remains high because the gain accrues disproportionately to those already enjoying better health. The health system also has the responsibility to try to reduce inequalities by improving the health of the worse-off, wherever these inequalities are caused by conditions amenable to intervention. The objective of a good health system is really efficacy at two factors: the best attainable average level - goodness - and the smallest feasible differences among individuals and groups -fairness. A gain in either one of these, with no change in the other, constitutes an improvement, but the two may be in conflict. (World Health Report p. 26).

In other words a good health system needs to be measured objectively in terms of its effectiveness and equity and subjectively in terms of the well-being of its consumers.

McKee (2001) argues that the WHO study has attempted some innovative work in comparative health care system evaluation, by introducing the construct of stewardship (associated with active involvement in health promotion) and a conceptual framework to target goals of health care, as well as attempting to explore the impact of input variables such as medical health care costs on physical health outcome variables. He cautions, however, that, whilst the health report highlights the many diverse activities that may enhance or restore health, these are not necessarily incorporated in the national health accounts. Furthermore health improvements may be attained through implementation of social policies such as reduction of accident through vehicle safety measures, or other determinants such as a nations' established dietary patterns. Moreover a growing interest has 
developed in agricultural policies and the development of consumer concerns frequently opposing industrial interests. Finally the data may be fragmentary and thus unreliable in instances where countries do not have adequate information concerning population size, education and health expenditure.

\section{Comparative studies on mental health and psychological well-being}

There is also an interesting and important empirical literature on cross national differences in subjective well-being (Diener et al, 1995; Kirkcaldy et al., 1997; Veenhoven, 2000). Studies attempt to establish empirically the correlates of national well-being, such as economic affluence and political democracy. Some of these studies considered national care systems. For instance, Veenhoven (2000) compared social security systems and found that people are roughly as happy in countries with lavish welfare as in equally affluent countries where provision is more modest. This suggests health care has only a modest impact on self-reported happiness. The health care system, so far, has not been considered in that way.

At the individual level, well-being researchers have noted that health and happiness are closely linked (Arygle, 2001; Myers, 1993). However this relationship is complex and reciprocal with many different hypothesized moderator and intervening variables. Some researchers have argued that health is a necessary predeterminant for subjective wellbeing. In that view well-being is likely to depend partly on the effectiveness of the national health care systems as well as private care, the individual's ability to pay for it, as well as the acuity and chronicity of their illnesses. Others have argued that subjective well-being is more powerfully determined by individual difference factors, in particular by personality traits such as perceived fate control and extraversion, the latter of which may be biologically determined. In that perspective, the national health care system will hardly affect subjective well-being.

The sociological and psychological explanations are not in conflict, though they differ jn three major ways: first the amount of variance they believe specific factors contribute to individual/national happiness/well-being; second the extent to which they believe it is possible to influence well-being/happiness through social policy implications, and third, the mechanisms and processes by which the two factors are reciprocally interactive. By and large economists and sociologists, more than psychologists and psychiatrists believe happiness may be significantly influenced by social policy decisions.

Various studies have reported cross-national analyses of socioeconomic data (for instance, Furnham et al., 1994. 1996). Kirkcaldy et al. (1997) explored the relationship between national differences in personality, socioeconomic situation and work-related attitudes. They showed that a substantial proportion of the variance in subjective well-being was explained by economic measures, particularly gross domestic product, suggesting a moderate relationship between happiness and wealth of a nation. It was the relationship with the work-related attitudes rather than personality factors that was most related to wealth:

nations high in psychological well-being were less competitive and attached less importance to money ... subjective well-being represents an ongoing state of psychological wellness (Diener, 1984) which as such would appear to bear little logical association with hard-driving and materially oriented traits such as competitiveness and evaluation of money. The results suggest that individuals with instrumental beliefs and commitment as well as achievement orientation, but who are cooperative and not exclusively materially oriented, have a higher well-being. (Kirkcaldy etal., 1997)

One of the most conspicuous findings was the relationship between cooperativeness (the obverse of competitiveness) and quality of life (assessed by the human development index). The argument is that initially social and economic competitiveness has a positive driving effect on quality of life, but once a particular level is reached a plateau occurs, and further competitiveness (as in industrial countries) starts to become counterproductive.

As yet research has not attempted to verify whether the ratings of medical health systems across nations in any way relate to other health outcome variables, particularly in the domain of psychological health. The purpose of this study was to address this shortcoming. Figures for the United States in 1996 indicate that, of the S943billion expenditure in health care, 7 per cent went into mental health care. Estimates of the indirect costs of all mental disorders to the US economy are around $\$ 79$ billion, most of which derives from morbidity and decrease in productivity due to illness. It has been calculated that mental disorders account for more than 15 per cent of the burden of disease in the 
economy, with some of the main ten causes being bipolar disorders, depression, schizophrenia and obsessional - compulsive disorders.

In a Dutch study, Meerding et al., (1998) reported that a substantial proportion of health costs was attributable to mental disorders. Mental retardation is ranked first, dementia third, depression and anxiety fifteenth, schizophrenia twenty-third, drug and alcohol misuse thirty-first, and a non-differentiated group of mental ailments ranked fourth. They further reported that mental disorders are responsible for almost one-third $(28.4 \%)$ of the budget that could be assigned to diagnostic groups.

The World Health Organisation appears at present to neglect (a) inclusion of subjective reports of health outcome variables, (b) measures of mental health, and (c) salient, relevant intervening variables. Several reasons invite considering outcomes in subjective well-being. One is that well-being may decline when we grow too old, even when free of disability. A second reason is that we may live better with physical limitations than with mental problems and that investment in mental health is thus more productive. Thirdly, effective health care may be detrimental to well-being, for instance when it enforces a joyless lifestyle.

Life expectancy has frequently been used as one of the variables which reflects the medical health efficacy of a nation. The problem remains as to whether success in lengthening life is not achieved at the cost of overall life satisfaction. More specifically, adhering to a healthy lifestyle may not imply an intrinsically enjoyable one, since it forbids many of the mundane pleasures of life, enforcing a more rigid diet and increasing nutritional awareness. Another interesting hypothesis is related to whether there is a natural limit to mental capacity and vitality. Finally success in reducing physical disabilities as measured by DALYS ('disability adjusted life years', a measure of the burden of disability and premature death resulting from illness) may not be the key to successful health care because it may not be associated with superior psychological health.

\section{Present study}

This study will be in the psychometric tradition: multivariate analysis of national data to explore health-well-being patterns. It was the primary goal to test hypotheses predicting plausible relationships between the health efficacy of a nation and various specific variables of subjective well-being and health behaviour. As yet few attempts have been made to relate these World Health expert ratings to other existent cross-cultural data bases which specifically monitor health outcome variables. Despite obvious methodological deficiencies inherent in such attempts at cross-cultural comparison (Van der Vliert et al., 2000), this form of health evaluative research is creative and provides insight for future social policy making. It not only allows for direct hypothesis testing but further provides correlational evidence of the relationship between macroeconomic variables.

This study will marry various data bases to the World Health Report data to explore correlates of the efficiency of health systems. It will follow the methodology of the abovementioned studies (for example Furnham et al., 1994, 1996; Kirkcaldy et al., 1997). Several tentative hypotheses are formulated below. Essentially, there will be significant differences between those nations who enjoy superior health systems and those who exhibit inferior health systems (as defined by the rankings in the World Health Report) in terms of positive and negative affect as well as other behavioural indicators of psychological well-being. A number of specific questions will be focused on, using the various cross-cultural data bases. These include the following:

\subsection{Questions}

- Do national health care systems really differ in terms of physical health outcome?

- Does good health care result in enhanced psychological health such as happiness for a greater number of the population (and a more equitable distribution)?

- Is it plausible that investment in mental health will be more conducive to happiness and, in turn, mental well-being?

- Are medical health and socioeconomic factors independent, compensatory or complementary in their role as contributors to mental health (psychological well-being)? 


\subsection{Method}

Several data bases were incorporated in the study, including the following:

- Veenhoven's (2001) World Database of Happiness, which lists research findings on satisfaction with life as a whole. A subset from this database contains the distribution of responses to single questions about this matter in general population surveys all over the world (catalogue of happiness in nations). From this collection we use average happiness in nations (means), dispersion or inequality of happiness (standard deviations) and happiness adjusted life years (a combination of average happiness and life expectancy, analogous to disability-adjusted life years).

Attempts will also be made to explore 'inequalities in life outcome measures' which correspond to distribution and fairness in psychological health (and so presumably are related to the WHO measures of equality and distribution of health care). For this purpose variation in the outcome variables will be assessed using SD (standard deviations) for happiness and subjective health.

- Eysenck's trait 'neuroticism' (national means for neuroticism were taken from Barrett and Eysenck's (1984) original 24-country normative data base).

- Diener's database of 'subjective well-being' (SWB) in nations (Diener et al., 1995; Oishi et al., 1999). The authors reported mean scores on subjective well-being for 55 nations. Their scores of average SWB in nations are partly based on the general population surveys that figure also in Veenhoven's list of happiness in nations (above). They added nations to that list where happiness was only assessed in student samples. From these student samples they also derive estimates of 'negative' and 'positive' affect.

- Suicide rate: (national rates for accidents and suicides International Classification of Disease (ICD) E950-E959; deaths by suicide or resulting from self-inflicted injury were expressed as cases per 100000 inhabitants for the years 1987-1995; taken from Eurostat and United Nations Demographic and Accounts Statistics Yearbook).

- WHO statistics of 'Health indicators' incorporating the following:

o DALE (disability-adjusted life expectancy) is estimated from the fraction of the population surviving to each age, calculated from the birth and death rates, inci dence of each disability at each age, and the weight assigned to each disability); distribution of responsiveness (in fulfilling the population's expectations); two factors of responsiveness (autonomy, confidentiality, choice or provider or facility, dignity, quality of basic amenities, access to social support networks, respect of persons, and client orientation), goal level and goal distribution,

o fairness (this refers to the risk each household faces that to whether the costs of the health system are related more to an individual's ability to pay than to their level of illness. A fair system ensures that low-income individuals are not forced into poverty as a result of their illness);

o overall goal;

o expenditure (costs incurred for the health system);

o health level;

o overall health; overall attainment is an absolute measure, but it provides little insight about how the outcome was attained compared to the resources of a nation: hence achievement relative to resources was used as the critical index of a health system's performance $\{$ WorldHealth Report 2000).

- The economic variables used in this study include GDP (gross domestic product), HDI (human development index, a combined score indicating national development) and economic growth. The research data were reported in The Economist (1995) and generally refer to national statistics for the year ending 1993; they are available for several years for approximately one hundred nations.

Major variables to be used in this project are listed in Table 1 above. 


\section{Results}

The first task was to determine how the various countries cluster according to the data collected. Initially we performed cluster analysis as a multivariate statistical procedure for detecting natural groups in the data set using the eight health indicator variables. The technique of cluster analysis 'resembles discriminant analysis, in which the researcher seeks to classify a set of objects into subgroups although neither the number of subgroups nor the members of the subgroups are known' (Wilkinson, 1988, p. 375). In this instance we adopted K Means clustering involving a splitting method, not necessarily hierarchical, to partition the objects (countries) into a selected number of groups (dichotomized into two groups on this occasion) by maximizing between-cluster relative to withincluster variation, hence similar to performing a one-way analysis of variance where the groups are unknown and the largest $F$-value is sought by reassigning members of each group' (ibid.). The clustering technique implements algorithms which are outlined by Hartigan(1975).

\subsection{Country groupings}

Essentially two distinct clusters were extracted (Table 2) based on profile similarity on the health indicator subscales, the first comprising 21 nations, including such countries as Roumania, Iraq, Sri Lanka, Yugoslavia and Egypt. In contrast, there were the 32 nations which constituted the second cluster, and included diverse nations such as Israel, Canada, Australia, Finland, Switzerland, the United Kingdom, Greece and Germany. Subsequently a series of univariate F-tests verified that these two clusters were substantially different on all nine health indicators, in particular overall goal attainment, expenditure, distribution and goal level, and, not unexpectedly, overall health performance.

The indicators 'overall goal attainment', 'distribution' and 'expenditure' emerge as very good discriminators between nations. From the two clusters that were generated on the basis of their work attitude profile, the first cluster displayed lower rankings on the DALE index, distribution, goal level, goal distribution, fairness, overall goal, expenditure, health level and overall health performance scores compared to the second cluster nations (for example Australia, Belgium, Canada, USA).

A series of univariate F-tests were computed to determine whether these clusters of nations differed in their economic profiles. The first cluster of low health care nations did not differ significantly in terms of inflation rate $(F(1,48)=1.82, \mathrm{p}>0.05)$ compared to the superior health care nations, nor were there significant differences reported in economic growth $(\mathrm{F}(1,48)=1.39$, n.s. $)$. The nations of the second cluster yielding higher scores on a variety of health system indicators were, however, significantly richer in terms of GDP (cluster I: $\mathrm{M}=1647$ SD 1266.31, cluster II: $\mathrm{M}=17780.69$ SD 9368.56; $\mathrm{F}(1,48)$ $=52.37, \mathrm{p}<0.001)$, and these were in fact the countries which had significantly greater expenditure on their health care systems.

\subsection{Psychological health and subjective well-being}

The second phase applied univariate F-tests to analyse whether the subjective reports of well-being profiles were statistically different.

If this empirical dichotomization based solely on health evaluation variables has anything meaningful to say about other real-life data in a country, for example psychological well-being (state of happiness, subjective well-being, neuroticism, positive and negative affect) then using these groups should be useful in predicting health-related variables, for example accident rates, suicide and criminal activity. This is an example of an external validation significant test of the cluster solution (Aldenderfer and Blashfield, 1984).

Of the eight variables selected (all of which had been collated from often quite distinct cross-cultural data bases using comprehensive questionnaires to assess the constructs involved) five emerged as statistically significant at the level of $p<0.02$. They are happiness $(F(1,37)=20.53, p<0.001)$, satisfaction with home life $(F(1,31)=15.25, p<0.001)$, work satisfaction $(\mathrm{F}(1,31)=13.75, \mathrm{p}<0.001)$, subjective well-being $(\mathrm{F}(1,35)=27.17, \mathrm{p}<$ $0.001)$ and accident rate $(F(1,32)=7.39, p<0.02)$. There was no evidence of differences being observed on negative affect, suicide rate, neuroticism or criminal rate. 


\section{Correlations between variables}

Correlational analyses are reported in Table 5. Happiness, subjective well-being and life satisfaction show the most consistent and highest correlations (correlations with health level and overall health ratings ranged between -0.50 and -0.59 ). Nations with low ratings in health level care and effectiveness of overall health care were more likely to exhibit high accident and suicide rates (correlation coefficients ranging between +0.44 and +0.60 ). Inferior psychological well-being, as measured by trait neuroticism and negative affect, was unrelated to a nation's health performance ratings. This suggests that good care in the domain for physical health does not necessarily add to national mental health. A total of $n=41$ completed nation scores for the first column correlations. It was not possible to control adequately for the extraneous effects of differences in material affluence using non-parametric statistics across all variables because nations were nearly always ranked. Some distinct parametric statistics were subsequently conducted using Partial correlations controlling for the potentially confounding effects of differences in GDP, and the significant effects persisted. More specifically, the correlation between but the correlation was still highly statistically significant $(r=-0.58, p<0.001)$ as was the correlation between health expenditure and happiness $(\mathrm{r}=-0.54, \mathrm{p}<0.001)$. Hence the superior subjective well-being reported by the better 'health-provided' nations could not be explained by GDP alone; that is, it cannot be due to superior health-ranked nations simply being richer. On the other hand, the expenditure on health care remains significantly associated with well-being.

Owing to the interrelatedness of the various health indicator scales, further statistical analysis was confined to those scales of subjective and objective well-being (happiness and accident rate) which had displayed the highest overall correlation with the health indices. Stepwise multiple regression analyses were subsequently computed to identify the specific determinants of well-being outcome variables. The two health performance variables, goal and health level (beta coefficients of -0.61 and -0.38 respectively), explained approximately two-thirds of the total variance observed in subjective well-being across nations, and health level emerged as the single significant predictor of accident rates, explaining one-third of the variance (Table 6).

The scattergram below (Figure 1) reveals the relationship between happiness and health level. Scattergrams provide additional information to bivariate statistics because (1) they visualize the degree of relationship, that is, concentration of the cases around a regression line, (2) they allow a view on the shape, for instance you can see whether the relation is linear or not, (3) they bring possible outliers to the attention, and (4) they show how the cases (countries) fit the pattern which helps to generate explanations. Dispersion of happiness (or health) in a country is a measure of inequality. Inequality in society is mostly measured by input, such as income or access to medical care. Dispersion of happiness/health measures equality of output in society.

Clearly those nations with favourable rankings (closer to 1), and thus superior health levels, also displayed the highest happiness scores $(r=-0.64, p<0.001)$.

When dispersion in happiness scores are plotted as a function of health level rankings (Figure 2), a similar linear relationship is found, but on this occasion the correlation is positive, suggesting that nations with inferior health care systems (high rankings in health level) were more likely to exhibit high inequality in their happiness ratings. 
Figure 3 illustrates that the relationship between fairness in health care and happiness was of a similar magnitude of effect to that reported between health level and happiness (cf. Figure 27.1) $(r=-0.69, \mathrm{p}<0.001)$. Nations with greater fairness (financial protection against ill-health) in their health care costs are more likely to show superior subjective well-being, as reflected in the happiness scores.

Finally, countries who were fairer in cost distribution of health care exhibited significantly less dispersion in their happiness scores (more equality in population's happiness ratings); see Figure 4.

\section{Discussion}

The World Health Report was an attempt to explore the strengths and weaknesses of diverse health care systems and to enable cross-culture comparisons to extract specific determinants of health care performance. It is argued that the three desirable goals of health care systems are improvement in the health of the population and reduction of inequalities in health, financial protection regarding the costs of contribution to health care, and enhancing responses to the expectation of the population.

task in sociometric and econometric analysis of medical care services. Much can be learned from international comparisons of medical health care, in exploring both similarities and differences in the development and structure of health care systems. The strategy in this study was to try and identify whether, and to what extent, the measures of health care effectiveness relate to other variables to do with general health, more specifically psychological health and/or subjective well-being.

\subsection{National health care systems and physical health outcome}

The major findings using the cluster analysis suggest that two clear groups of nations are generated, one encompassing those countries with highly developed medical health care systems (including the majority of Western European and Nordic countries, as well as nations such as the USA, Australia, UAE and Israel, and Pacific Rim countries such as Singapore, Korea and Japan), and the other cluster representing nations in the process of developing or that are underdeveloped (including Eastern European nations and 'Third World' countries). When these groups were compared in terms of specific health indicators, the magnitude of the effect size was highest for the health system variables 'overall goal', 'health expenditure', 'distribution' and 'goal level', and the outcome variable, 'overall health performance'.

Clearly these differences are in part due to socioeconomic differences between nations, and some would argue, with Avery:

World leaders, especially of the G8, should review the globalisation of the world economies with a view to removing unpayable debts, providing targeted economic aid directed towards sustainable development ... International agencies should accelerate the development of health and social welfare plans, provide grants for education and training, and encourage research into the aid directed towards tackling major diseases, improving education, primary health care, and health education promotion, and encouraging sustainable development in agriculture (Avery, 2002) 
But clearly the differences observed in health care system performance are not limited to expenditure, as those nations with the highest expenditure on health care are not necessarily ranked as the most efficient in their performance. On the other hand, in order to secure comparatively good medical health care, a minimum health expenditure programme is required, and nations investing beyond that level may not necessarily be reaping the benefits in terms of increased efficiency. At a correlational level, we may observe clear significant correlations between health efficacy and expenditure across nations, but this relationship may attenuate when doing cross-cultural comparisons between wealthy, industrialized nations.

5.2 Health care performance and psychological health (quality and equity) Furthermore, as shown in Table 4, some intriguing patterns emerge: individuals in high health-effective countries appear to report better psychological well-being in terms of being more satisfied both in life and with work, and experiencing higher subjective well-being and happiness, although there was no evidence that they were more psychologically stable (in terms of trait neuroticism), nor were there significant differences reported on negative affect or suicide rate. At the more objective outcome variable level, nations assigned as having superior health care performance ratings did at the same time reveal lower rates of accidents per 100000 inhabitants. This finding appears consistent with those of previous statistics (The Economist, 2001) in which accident rates as measured by deaths per 100000 inhabitants due to injuries and poisons reveal that the rates were highest for Russia (203.4), Lithuania (142.6), Hungary (92.3), Finland (73.5) and Poland (72.4), and lowest for Sweden (38.6), Greece (39.1), Ireland (39.8), Norway (42.5) and Austria (42.5). Moreover there was a tendency for nations with well-developed health care systems to report fewer suicides, although the difference did not emerge as statistically significant, probably because of the greater dispersion in suicide rate observed among the less well-developed nations.

Happiness emerged as the single variable which consistently and significantly correlated with each and every one of the health variables. The mean correlation coefficient was 0.74 . Moreover, when we analysed the interrelationships between health systems and dispersion in happiness (using standard deviations of happiness), there was evidence that the nations with superior health care systems including 'fairness' within their health care were also those which exhibited least inequality in their happiness data.

The linear regression analysis revealed that two of the eight health variables were significant determinants of happiness, explaining approximately two-thirds of the variance observed. Again it was interesting that health expenditure did not emerge as one of the major predictors of happiness. Nations with more favourable rankings in their health care system with respect to goal level and health level were likely to exhibit higher happiness scores. Moreover health level emerged as the single significant predictor of accident rate, with nations with inferior health systems displaying a higher incidence of accidents. It is possible that such countries invest more in time and money educating its citizens about the risks of accidents and their prevention as well as making efforts to ensure that accidents are prevented. 
In another study, Kirkcaldy and Fumham (2000) explored the incidence rates of accidents, deaths due to suicide and self-inflicted injuries, as well as deaths resulting from car accidents. They found no evidence of any relationship between negative affect and the outcome variables. Conversely subjective well-being was significantly negatively correlated with incidence of accidents as well as deaths resulting from motor (driving) accidents.

Two central issues arise from this study. Firstly, why is there no link with measures more closely associated with mental health such as neuroticism and negative affect? One methodological explanation may be that this is an artefact due to limited cases, in which case the data may not be truly representative. This kind of explanation is supported by the fact that health care quality does relate to subjective well-being, while mental health and subjective well-being are typically closely linked. Alternatively, a substantive explanation would be that investment in physical care may be at the cost of mental heath care. There is evidence that, although mental disorders represent a substantial proportion of the illnesses witnessed in Western industrialized countries, only about 6 percent of the expenditure in medical health care is directed towards mental health. In other words, somatizing cultures would be more inclined to push investments in physical health care.

Secondly, why is health care (quality/fairness) linked to subjective well-being (level/ dispersion)? There are several explanations here. It may be that the effects of good care improve physical health, which in turn quite plausibly makes people feel happier. In addition, it may be that the effects of well-being on producing happier citizens may lead them to vote more for investment in public health care.

So the question that remains is, does health effectiveness lead to satisfaction or vice versa? More importantly, what are the other variables that may moderate this relationship? Or is it that macro economic variables are intervening? Our analysis showed that GNP was highly significantly related to both well-being $(r=0.82)$ and health efficacy $(r=0.70)$.

Thus variables such as weather, natural resources and stable (democratic) governments may affect GDP, which in turn predicts both subjective well-being and health efficacy, even though the variables themselves may be loosely related (see Figure 6). This is extremely important given that so much is spent on health care in an attempt to improve subjective well-being, which may or may not be effective.

Added to this, the analysis is correlational, and we have no details of causal relationships. What did emerge was that subjective well-being and health effectiveness were significantly correlated even after controlling for potentially confounding effects of socioeconomic data (GNP and economic growth), which suggests that economic factors in themselves are not sufficient to explain the differences, although nations with more money to spend on health care overall clearly experienced superior physical and psychological well-being.

Other more complex multidimensional models listed below involving socioeconomicpsychological variables intimately interrelated are probably more accurate representations of the underlining causal mechanisms involved.

When we make comparisons between different countries, it may be useful to further distinguish between how satisfied the recipients or consumers of the health systems (patients and clients) and the providers (medical and allied personnel) are. Some 
European studies have looked at this issue. Mossialos (1996) examined public perception of various European health care systems in terms of the degree of satisfaction in the 15 EU states. Dissatisfaction from a 'consumer' viewpoint was highest for Italy (59.4 per cent being either fairly or very dissatisfied), followed by Portugal (59.3 per cent), Greece (53.90 per cent), the UK (42.9 per cent) and Ireland (29.1 per cent). In contrast, satisfaction was highest for Denmark ( 90.0 per cent being either very or fairly satisfied), Finland (86.4 per cent), Netherlands (72.8 per cent), Luxembourg (70.1 per cent), Sweden (67.3 per cent) and Germany (66.0 per cent). This is interesting because these nations correspond to those European nations ranked intermediate in our listing (rankings between 9 and 18 of 26 EU nations). Public expectations of resources in medical health care have been supposed to have major health policy consequences, which will have an impact on the investment in health care and scrutinizing of health care reform.

On the other hand, others (for example BMJ Survey, 2001) have examined a league table of unhappiness among the providers (medical doctors) themselves as a function of country. Among the least satisfied European countries were the UK (over two-thirds were either very unhappy or unhappy) followed by Spain (66.7 per cent), Belgium (64.3 per cent), Greece (58.3 per cent), Italy (57.7 per cent) and Ireland (52.4 per cent). Certainly there may be some discrepancies between what consumers perceive as satisfactory and how suppliers, that is the medical profession, evaluate their work.

Certainly, the finding that positive affect, but not negative affect, may be associated with health performance of a nation demands discussion. Future research may try to gain measures of the magnitude of investment in psychological health care, and then correlate these economic measures with mental well-being outcome variables.

Some critical remarks about the study concern the absence of psychological wellbeing data for those nations with vastly inferior health care listed among the approximately 190 countries in the World Health report (Angola, 181; Central African Republic, 189; Chad, 178; Ethiopia 180; Guinea-Bissau, 176; Lesotho, 183; Liberia, 186; Malawi, 185; Mozambique, 184; Myanmar, 190; Nigeria, 187; Sierra Leone, 191; Somalia, 179; Swaziland, 177; Zambia, 182.) In contrast, our data did include comprehensive data for the majority of the most highly rated nations (France (1), Italy (2), San Marino (3), Andorra (4), Malta (5), Singapore (6), Spain (7), Oman (8), Austria (9), Japan (10), Norway (11), Portugal (12), Monaco (13), Greece (14), Iceland (15) and Luxembourg (16)). Consequently the worst of our data base's health system nations do not correspond with the world's lowest values in health care. This would have the net effect of attenuating any differences between groups.

Criticisms of the psychometrics of the measures include rank-ordering, frequent reliance on single-item scales, and item overlap. Furthermore it is likely that there are curvilinear relationships between such variables as financial and economic factors: 'cost of health care', and psychological health, with increments in health being most noticeably observed among those nations with relatively scarce economic reserves for health care. As we approach the more developed, and financially costly, health care systems, a plateau is probably attained in which little observable change is witnessed with increases in health care expenditure.

Another important point is that the assumption that the efficiency of a health care system (in terms of physical health 'disability-adjusted life expectancy' and cost effectiveness) necessarily relates to better (more intensive and comprehensive 'psychological') care may be invalid. We have no knowledge of what percentage of the health care costs actually goes into counselling or therapy, thus affecting psychological well-being. Alternatively it could be argued that nations who enjoy better physical health will more likely exhibit improved psychological well-being. This issue may be resolved by looking at the magnitude of the correlation coefficients between aspects of psychological well-being and 'expenditure' (cost of health care) as opposed to 'overall goal attainment' (efficacy of health care). Presumably differences should be observed. Our table reveals no such difference, with the exception of 'suicide' and 'accident rates': here we found that, although these behavioural variables were not significantly related to cost of health, they were indeed significantly related to health attainment.

Nord (2000) provides a succinct analysis of the method of data collation in the WHO report: 
Decision makers who, in spite of the above criticisms, are inclined to regard the summary indices of the World Health Report as useful, should be aware that the assignment of weights to different aspects of responsiveness and overall goal attainment is difficult and may be culturally dependent. No country should uncritically accept the weights suggested by the WHO as being scientific or objective or correct. Every country should judge carefully whether the WHO weights fit with the country's own values, and thereby judge the relevance of the various indicators and indices for its own policy making.

Certainly, notwithstanding the interesting results of our study, health care cannot be completely divorced from other socioeconomic factors such as (1) basic infrastructure (for example roads, schools, water supply, electricity and lighting), (2) law, order and corruption, (3) family size and number of inhabitants per household, and (4) the economic prosperity of the country.

Despite all the above-mentioned methodological shortcomings, it is however important to do this research to examine empirically these relationships. Too much ideology and not enough empirical research has been prevalent. Health is a political battlefield, and we need more dispassionate research to explore causal relationships in this domain. If there are errors of measurement, the relationships we have observed between health performance effectiveness and subjective well-being, whilst being statistically significant, are likely to be an underrepresentation of the true magnitude of the association.

\section{Acknowledgments}

We would like to express our thanks to Priv. Doz. Dr Georg Siefen, Medical Director of the Westfalia Clinic for Child and Adolescent Psychiatry and Psychosomatic, Marl-Sinsen, who kindly read one of the earlier draft versions of this text and made suggestions for improvement.

\section{References}

Aldenderfer, M.S. and R.K. Blashfield (1984), Cluster Analysis: Quantitative Applications in the Social Sciences, London \& Bevely Hills: Sage.

Argyle, M. (2001). The Psychology of Happiness, London: Routledge. Avery, G. (2002), 'Comparative efficiency of national health systems', British MedicalJournal, 324, 48.

Barrett. P. and S.B.G. Eysenck (1984), 'The assessment of personality factors across 25 countries'. Personality and Individual Differences, 5, 615-32.

British Medical Journal (2001). 'Analysis of satisfaction among European doctors survey". BMJ website.

Diener. E. (1984), 'Subjective well-being". Psychological Bulletin. 95, 545-75. Diener, E., M. Diener and C.

Diener (1995), 'Factors predicting the subjective well-being of nations'. Journal of Personality and Social Psychology, 69, 851-64.

Furnham, A.. B.D. Kirkcaldy and R. Lynn (1994). 'National attitudes, competitiveness, money and work: First Second and Third World differences'. Human Relations, 47. (1), 119-32.

Furnham. A.. B.D. Kirkcaldy. and R. Lynn (1996). 'Attitudinal correlates of national wealth'. Personality and Individual Differences, al 21 (3), 345-5

Jakubowski, E. and C.R. Busse (1998), 'Health care system in the EU: a comparative study". Directorate Gener for Research, working paper. Public Health and Consumer Policy Service, European Parliament, SACO 101 EN, 111198

Hartigan, J. (1975), Clustering Algorithms, New York: John Wiley.

Kirkcaldy, B.D. and A.F. Furnham (2000), 'Positive allectivity, psychological well-being, accident- and trafficdeaths, and suicide: an international comparison'. Studio Psychologica, 42, (1-2), 97-104.

Kirkcaldy. B.D., A. Furnham and T. Martin (1997), National differences in personality, socioeconomic and work-related variables', European Psychologist, 3(4). 255-62.

McKee, M. (2001), 'Measuring the efficiencyof health systems. The World Health report sets the agenda but there's still a long way to go', British Medical Journal, 323, 295-6.

Meerding, W.J., L. Bonneaux, J.J. Polder. M.A. Koopmanschap and P.J. van der Meas (1998), 'Demographic and epidemiological determinants of health care costs in the Netherlands: cost of illness study", British Medical Journal, 317,111-5.

Mossialos, A. (1996), Satisfaction in Health Care Systems, Brussels: European Union.

Myers, D. (1993), The Pursuit of Happiness, New York: Avon Books. Nord, E. (2000), World Health Report 2000.

A Brief Critical Consumer Guide, Oslo: National Institute of Public Health

Oishi. S., E.F. Diener, R.E. Lucas and E.M. Suh (1999), 'Cross-cultural variations in predictors of life satisfaction: perspectives from needs and values'. Personality and Social Psychology Bulletin, 25 (8), 98090. 
Van de Vliert, E., E.S. Kluwer and R. Lynn (2000), 'Citizens of warmer countries are more competitive and poorer: culture or chance' Journal of Economic Psychology. 21. 143-65.

Veenhoven. R. (2000), 'Well-being in the welfare state: level not higher not more equitable", Journal of Comparative Policy Analysis: Research and Practice, 2, 91125.

Veenhoven, R. (2001), 'State of nations: world database of happiness", Erasmus University of Rottodam, Faculty of Social Sciences.

WHO (2001), The World Health Report 2000, Geneva.

Willinson, L. (1988), Systat: The System for Statistics, Evamston: Systat Inc. 
Figure 1 Happiness (Happy 2) as a function of rankings of the health level of nations

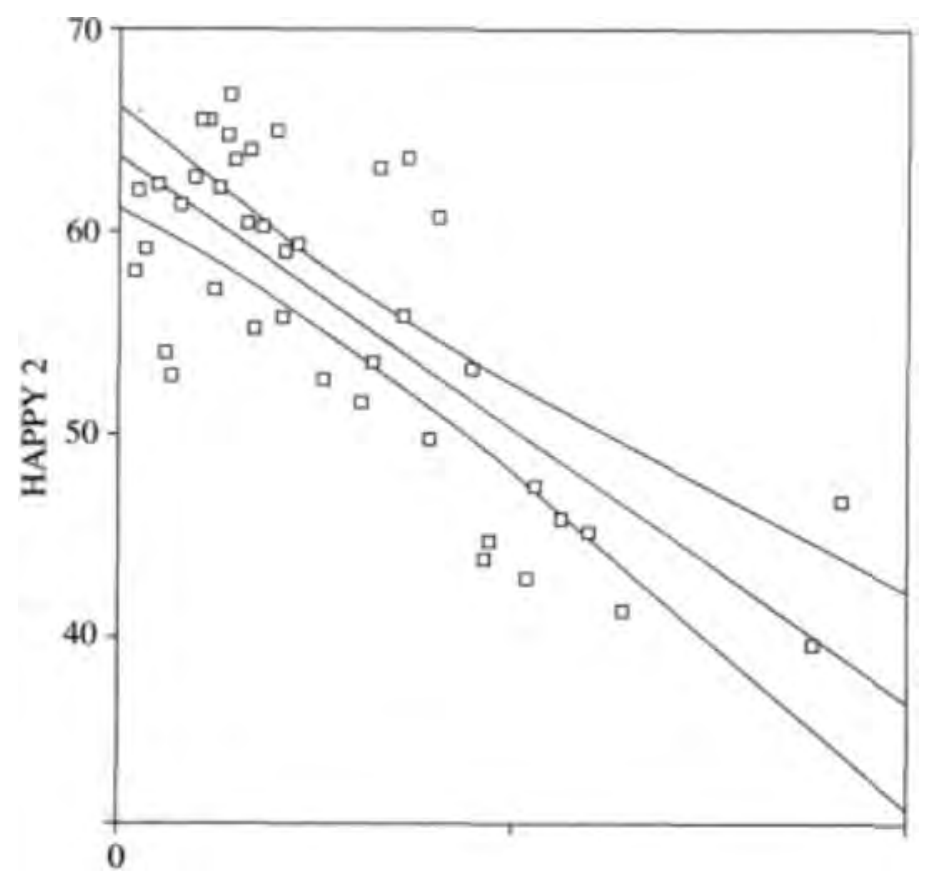

Note: High health level rankings imply inferior health levels. Low rankings mean superior health.

Figure 2 Inequality (dispersion) of happiness for various health level rankings of nations

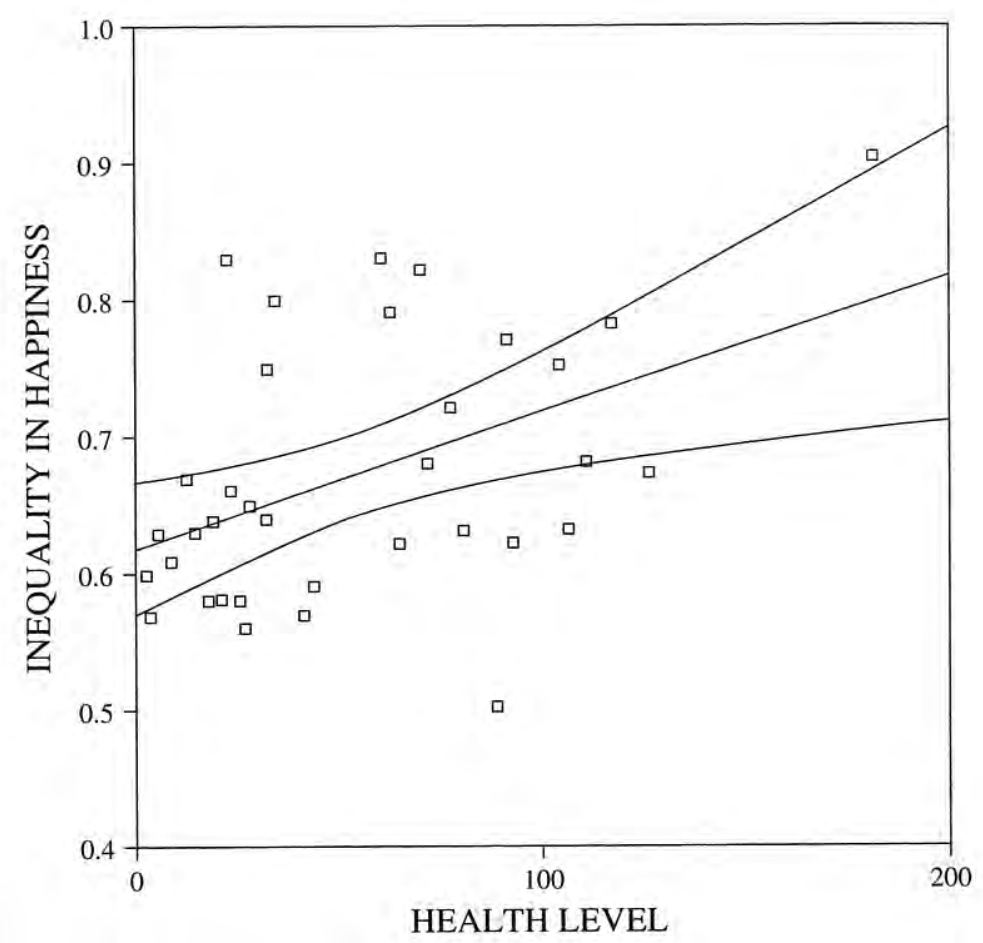

Note: Low fairness rankings are associated with superior health fairness scores. 
Figure 3 The relationship between fairness in health systems and happiness scores

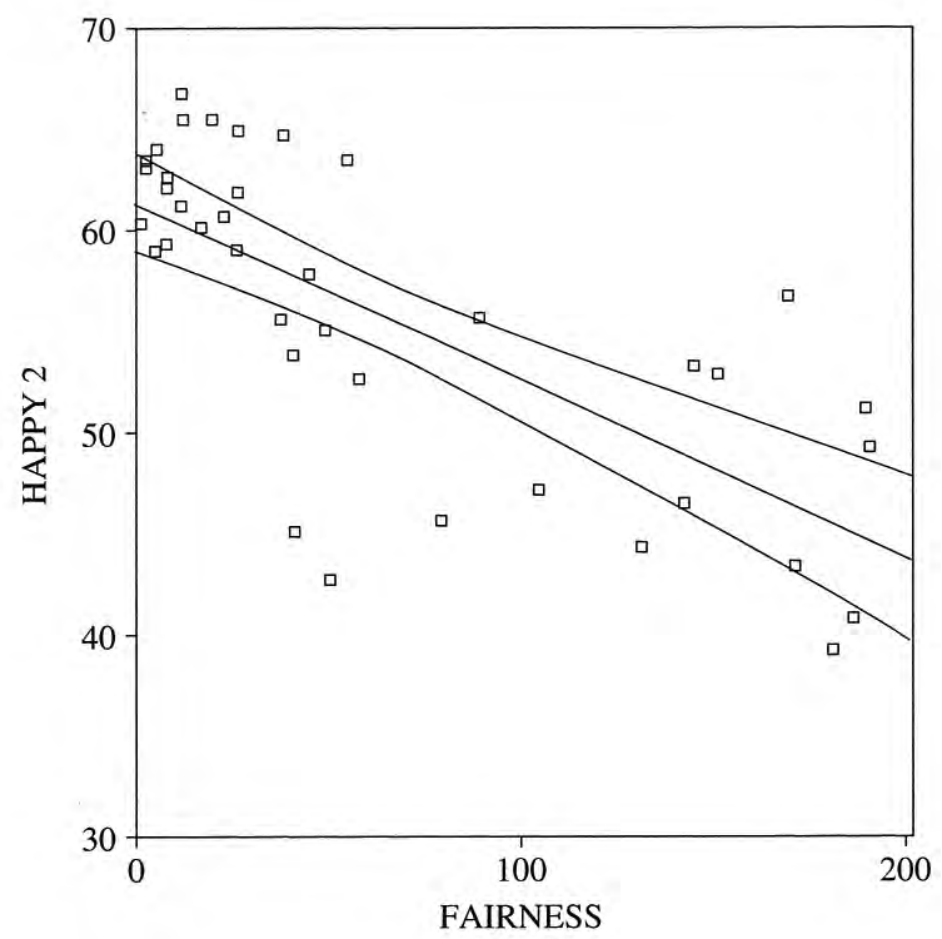

Note: Low fairness rankings are associated with superior health fairness scores.

Figure 4 Dispersion in happiness scores and its relationship to a nation's fairness rating in health care

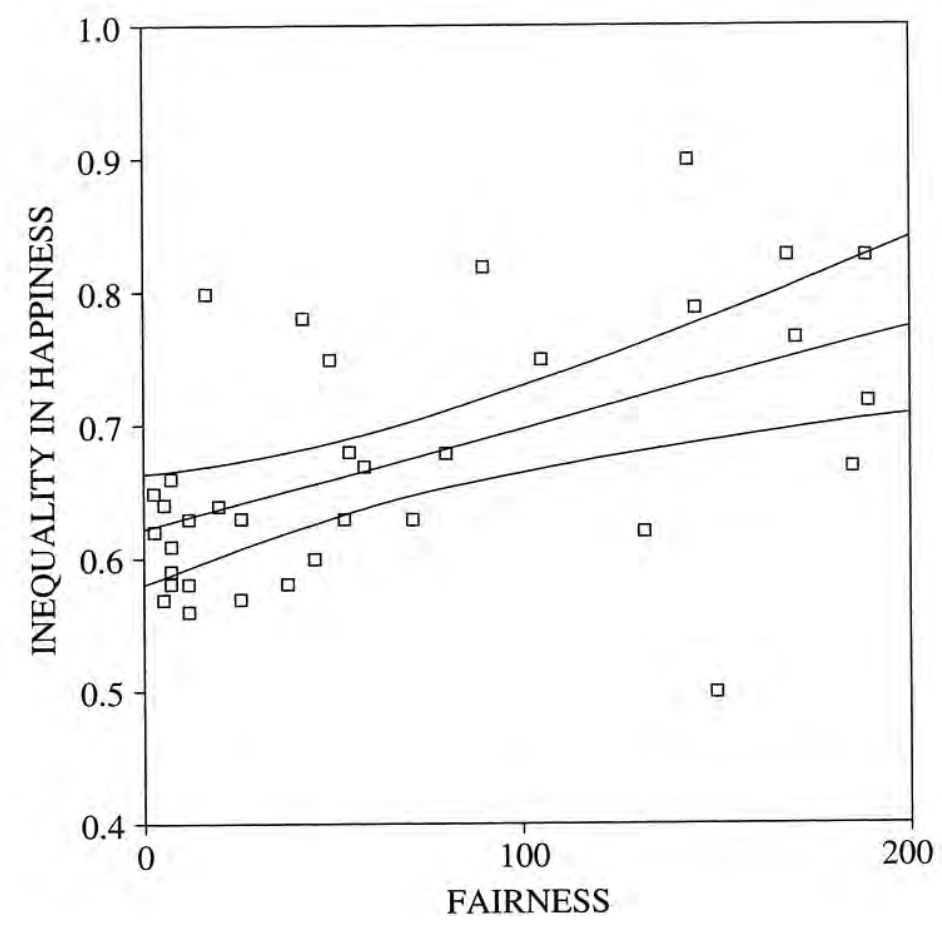

Note: Low fairness rankings are associated with superior health fairness scores. 
Kirkcaldy, Furnham, Veenhoven

15

Health care and subjective well-being in nations

Figure 5 A model of the relationship between well-being, health effectiveness and GNP

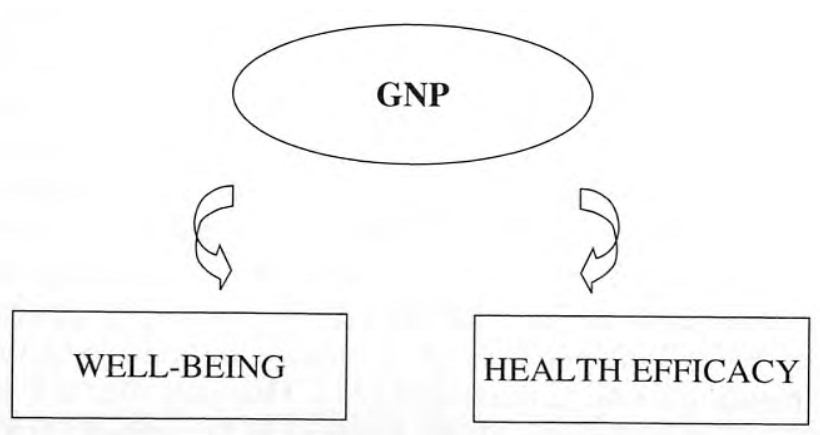


Figure 6 A multidimensional causal model of the relationship between geographical, economic and psychological variables and health care and psychological well-being

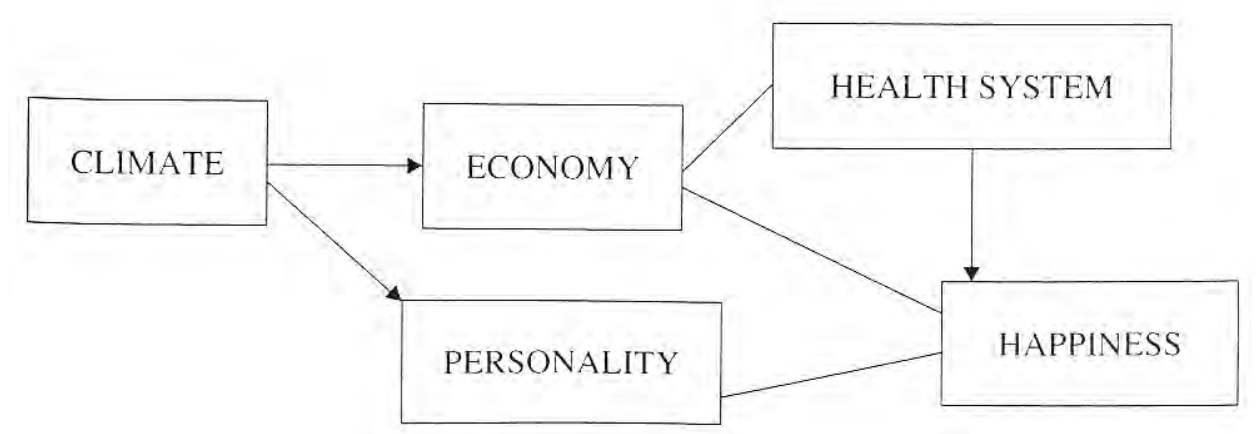


Table 1 Sociopsychological and economic variables

Intervening variables

Wealth and development

GNP

Growth

Outcome variables

Well-being

Life satisfaction

Work satisfaction

Positive affect

Happiness

Negative affect

Suicide

Accident

Health system indicators

Subjective health rating

DALE

Health level

Overall health

Input system variables

Distribution

Goal level

Goal distribution

Fairness

Overall goal

Expenditure
GNP per capita

Economic growth

Average self-reported life satisfaction

Average reports of work satisfaction

Population aggregate of positive affectivity

Average self-report for happiness

Negative affect

Suicide rates per 100000

Accident rate

Disability-adjusted life expectancy

Performance of level of health

Overall ranking in health attainment

Distribution of costs within health care

Responsiveness (goal level)

Equality of goal distribution

Risk each household faces from health costs

Overall goals set

Costs incurred by the health costs of a nation 
Table 2 Results of the cluster analysis and the differences between cluster

Case distance

\begin{tabular}{lr}
\hline Bangladesh & 150.12 \\
Brazil & 98.56 \\
Bulgaria & 140.29 \\
China & 101.12 \\
Egypt & 86.15 \\
Hungary & 124.48 \\
India & 112.48 \\
Iraq & 81.55 \\
Jordan & 90.10 \\
Lithuania & 109.35 \\
Mexico & 119.34 \\
Nigeria & 223.39 \\
Romania & 73.98 \\
Russia & 97.56 \\
South Africa & 161.66 \\
Sri Lanka & 79.16 \\
Syria & 50.27 \\
Turkey & 107.75 \\
Uganda & 195.50 \\
Venezuela & 116.34 \\
Yugoslavia & 85.77
\end{tabular}

Case distance

\begin{tabular}{lr}
\hline Argentina & 99.57 \\
Australia & 30.17 \\
Austria & 44.74 \\
Belgium & 38.75 \\
Canada & 33.93 \\
Chile & 164.66 \\
Columbia & 124.89 \\
CSSR & 77.05 \\
Denmark & 51.80 \\
Finland & 33.28 \\
France & 52.73 \\
Germany & 41.36 \\
Greece & 40.52 \\
Holland & 36.23 \\
Iceland & 32.16 \\
Ireland & 34.99 \\
Israel & 19.41 \\
Italy & 48.06 \\
Japan & 57.47 \\
Korea & 93.88 \\
Luxembourg & 47.46 \\
New Zealand & 51.37 \\
Norway & 47.85 \\
Poland & 148.47 \\
Portugal & 57.60 \\
Singapore & 75.98 \\
Spain & 44.74 \\
Sweden & 43.92 \\
Switzerland & 40.61 \\
UAE & 65.06 \\
UK & 40.91 \\
USA & 53.92
\end{tabular}


Table 3 A comparison of means (rankings) between clusters across all health indicators

\begin{tabular}{lcccc}
\hline & Cluster mean I & Cluster mean II & $\mathrm{F}(1,52)$ & $\mathrm{P}$ \\
\hline Output variables & & & & \\
$\quad$ DALE & 99.32 & 22.50 & 98.88 & $0.001^{* * *}$ \\
Health level & 92.23 & 36.09 & 33.20 & $0.001^{* * *}$ \\
Overall health & 103.05 & 24.75 & 113.83 & $0.001^{* * *}$ \\
System variables & & & & \\
Goal level & 102.14 & 22.38 & 108.90 & $0.001^{* * *}$ \\
Goal distribution & 95.50 & 14.94 & 67.63 & $0.001^{* * *}$ \\
Fairness & 118.14 & 36.03 & 43.65 & $0.001^{* * *}$ \\
Overall goal & 103.55 & 19.38 & 141.67 & $0.001^{* * *}$ \\
Expenditure & 103.55 & 20.63 & 135.08 & $0.001^{* * *}$ \\
\hline
\end{tabular}

Note: $\quad$ Let $* * *$ represent $\mathrm{p}<0.001$. 
Table 4 A comparison of subjective well-being between nations which are highly developed or underdeveloped in terms of their health effectiveness (happiness scores for $n=40$ nations)

\begin{tabular}{lccc}
\hline Subjective well-being & $\begin{array}{r}\text { Cluster I (low health } \\
\text { effectiveness) }\end{array}$ & $\begin{array}{c}\text { Cluster II (high health } \\
\text { effectiveness) }\end{array}$ & F-test \\
\hline Satisfaction home-life & $7.27(0.60)$ & $8.06(0.47)$ & $17.24^{* * *}$ \\
Job satisfaction & $6.92(0.64)$ & $7.63(0.45)$ & $13.75^{* * *}$ \\
Happiness years & $46.71(4.72)$ & $60.48(4.10)$ & $88.72^{* * *}$ \\
Subjective well-being & $-0.81(0.65)$ & $0.26(0.72)$ & $19.95^{* * *}$ \\
Positive affect & $2.39(0.43)$ & $2.61(0.65)$ & 1.03 \\
Negative affect & $1.37(0.47)$ & $1.11(0.29)$ & 3.78 \\
Trait neuroticism & $14.30(2.03)$ & $14.29(2.35)$ & 0.00 \\
Objective well-being & & $45.50(20.28)$ & \\
Accident rate & $85.57(64.29)$ & $14.73(9.14)$ & $6.60^{*}$ \\
Suicide incidence & $21.00(29.70)$ & & 1.05 \\
\hline
\end{tabular}

Note: $\quad$ Let $* p<0.05$ and $* * * / ?<0.001$. 
Table 5 Non-parametric correlations between health variables and specific dimensions of psychological health and behaviour.

\begin{tabular}{|c|c|c|c|c|c|c|c|c|c|c|}
\hline \multirow[b]{2}{*}{$\begin{array}{l}\text { Health } \\
\text { indices }\end{array}$} & \multicolumn{5}{|c|}{ Psychological well-being } & \multicolumn{5}{|c|}{ Negative health } \\
\hline & Happiness 2 & Work sat. & Life sat. & Well-being & $\begin{array}{c}\text { Positive } \\
\text { affect }\end{array}$ & $\begin{array}{l}\text { Inequality } \\
\text { in nation's } \\
\text { happiness }\end{array}$ & Neuroticism & $\begin{array}{c}\text { Negative } \\
\text { affect }\end{array}$ & $\begin{array}{c}\text { Accident } \\
\text { rate }\end{array}$ & Suicide \\
\hline DALE & $-0.79 c$ & $-0.37 a$ & $-0.52 c$ & $-0.49 b$ & -0.18 & $+0.59 \mathrm{c}$ & -0.09 & $+0.35(\mathrm{a})$ & $+0.34(\mathrm{a})$ & +0.02 \\
\hline Distribution & $-0.62 c$ & $-0.39 a$ & $-0.38 \mathrm{a}$ & $-0.40 \mathrm{a}$ & -0.18 & $+0.55 \mathrm{c}$ & -0.09 & +0.13 & +0.28 & +0.07 \\
\hline Goal level & $-0.85 c$ & $-0.60 c$ & $-0.60 c$ & $-0.62 c$ & $-0.38 \mathrm{a}$ & $+0.56 \mathrm{c}$ & -0.03 & +0.26 & $+0.34 \mathrm{a}$ & $-0.47 \mathrm{a}$ \\
\hline $\begin{array}{l}\text { Goal } \\
\text { distribution }\end{array}$ & $-0.69 c$ & -0.26 & $-0.42 \mathrm{a}$ & $-0.58 c$ & -0.28 & $+0.50 \mathrm{~b}$ & -0.13 & +0.30 & +0.15 & -0.10 \\
\hline Fairness & $-0.69 c$ & $-0.37 \mathrm{a}$ & $-0.54 b$ & $-0.58 c$ & -0.23 & $+0.53 \mathrm{c}$ & +0.08 & +0.31 & +0.23 & -0.31 \\
\hline Overall goal & $-0.84 c$ & $-0.46 b$ & $-0.55 c$ & $-0.62 c$ & -0.29 & $+0.62 \mathrm{c}$ & -0.07 & +0.26 & +0.27 & -0.35 \\
\hline Expenditure & $-0.84 c$ & $-0.51 b$ & $-0.68 c$ & $-0.70 c$ & $-0.39 a$ & $+0.56 \mathrm{c}$ & -0.11 & +0.26 & +0.22 & $-0.50 \mathrm{a}$ \\
\hline Health level & $-0.64 c$ & -0.20 & $-0.44 b$ & $-0.35 a$ & -0.10 & $+0.41 \mathrm{a}$ & -0.11 & +0.30 & $+0.48 \mathrm{~b}$ & -0.25 \\
\hline Over, health & $-0.67 \mathrm{c}$ & -0.27 & $-0.43 \mathrm{a}$ & $-0.47 b$ & -0.05 & $+0.62 c$ & -0.09 & $+0.36 \mathrm{a}$ & $+0.35 \mathrm{a}$ & +0.14 \\
\hline
\end{tabular}

Note: $\{$ Let $a=p<0.05, h=p<0.01$. and $c=p<0.001$ ) Low health rate scores correspond to high rankings (for example overall health rankings that were numerically low imply superior overall health systems). 
Table.6 Determinants of psychological well-being (outcome variables)

\begin{tabular}{lcccc}
\hline & & & $\mathrm{R}=0.90$, adj. $\mathrm{R}^{2}=0.80$ & $\mathrm{~F}(2,38)=82.80^{* * *}$ \\
Happiness & beta & $\mathrm{t}$ & $0.001^{* * * *}$ & \\
Goal level & -0.61 & -6.60 & $0.001^{* * *}$ & \\
Health level & -0.38 & -4.10 & $\mathbf{R}=0.59$, adj. $\mathbf{R}^{2}=\mathbf{0 . 3 3}$ & $\mathbf{F}(\mathbf{1 , 3 2})=\mathbf{1 6 . 9 1 * * *}$ \\
& & & $0.001^{* * *}$ & \\
$\begin{array}{c}\text { Accidents } \\
\text { Health level }\end{array}$ & +0.59 & +0.41 & &
\end{tabular}

Note: Let $^{* * *}$ represent $/ ;<0.001$. 